\title{
BACTERIAL LEAKAGE ANALYSIS OF ROOT CANAL OBTURATED USING SINGLE CONE TECHNIQUE WITH THREE DIFFERENT ROOT CANAL SEALERS AND THREE DIFFERENT CORONAL RESTORATIVE MATERIALS (IN-VITRO STUDY)
}

\author{
Samia Elsherief*, Sahar M Elmarsafy ${ }^{* *}$ and Abdel-Rahman Youssef ${ }^{* * *}$
}

\begin{abstract}
Introduction: The main aim of root canal therapy is adequate sealing to prevent reinfection with subsequent periapical disease.

The aim: The aim of this study was to compare the sealing ability of root canal filled teeth using three different sealers and three different restorative materials by bacterial penetration method during a 30-day period.

Materials and Methods: Seventy-two single rooted teeth were prepared using Protaper Next. Obturation was done using single cone technique .The teeth were randomly divided into three groups of 24 samples according to the sealer used as following; group 1: Bioceramic sealer (BS), group 2: MTA fillapex (MTA) and group 3: Tagdseal sealer (TG). The samples then randomly subdivided into 3 groups of 8 samples according to the coronal restoration of the specimens as following; subgroup A: Composite (Tetric Ceram + Tetric N Bond), subgroup B: Compomer (Compoglass F + Adhese SE) and subgroup C:Glass Ionomer (Ketac N + Ketac primer).Therefore, there was 9 final groups; I, II, III, IV, V, VI, VII, VIII, IX.After setting time, the samples were incorporated in a bacterial leakage model, using E. faecalis. Leakage was evaluated by turbidity in lower chamber in 30-day period. Statistical analysis was done using One-wayANOVA test, and post hoc pairwise comparison was done using Tukey test.
\end{abstract}

Results: The results showed that group I (BS - Composite) presented the lowest means of bacterial leakage after all periods of evaluation. On the other hand, the (MTA - Glass Ionomer) material showed the highest means of leakage. There was a significant difference between the means of the bacterial colonies recorded in the nine groups at one, 2 and 4 weeks; while at 3 weeks the difference was insignificant.

Conclusion : Bioceramic sealer with composite restoration showed the least bacterial leakage.

Key Words: single cone obturation, bacterial leakage, mineral trioxide aggregate-based sealer, resin-based sealer, bioceramic sealer, coronal restoration.

\footnotetext{
*Assistant Professor of Endodontics, Faculty of Oral and Dental Medicine, Cairo University, Egypt **Assistant Professor of Operative Dentistry, Faculty of Dental Medicine, Al-Azhar University, Egypt ***Assistant Professor of Microbiology and Immunology, Faculty of Medicine, Suez Canal University Egypt.
} 


\section{INTRODUCTION}

The outcome of endodontic therapy is correlated with quality of the root filling and coronal restoration. High quality root canal filling and adequate coronal restoration are expected to provide seal against further challenge by bacterial ingress and promotes periapical healing that is essential for long term of canal treatment success ${ }^{(1-5)}$.

The use of a root canal gutta-percha/sealer plays an essential role in providing a fluid, tight filling material ${ }^{(6)}$. Sealer enhances the adhesion between gutta-percha and dentin walls, acts as a lubricant; it also fills the minor irregularities and spaces between the gutta-percha cones and the dentin walls and can fill accessory and lateral canals (7). The type of sealers used plays a very important role to achieve this goal; in endodontic practice, there are different types of sealers as zinc oxideeugenol, calcium hydroxide, resin, glass ionomerbased sealer, silicone and resin sealers. Resin-based sealers have many merits, as setting in the moisture, insoluble in tissue fluids, adequate setting time and antibacterial properties ${ }^{(8)}$. Tgadseal is an epoxy matrix resin-based root canal sealer; it is easy to mix with excellent biocompatibility ${ }^{(9)}$. Mineral Trioxide Aggregate-based root canal has been generally used for treating root perforations, pulp capping, pulpotomy, and retrograde filling. Newer types of MTA-based cements, reported to have adequate biological properties MTA-based sealers are highly biocompatible, able to stimulate tissue regeneration, and have higher push-out strengths than conventional sealers. Recently a new formulation of MTA-based cement; MTA Fillapex ${ }^{\circledR}$ (Angelus, Londrina, PR, Brazil) was introduced as root canal sealer. Its satisfactory biological properties, antibacterial properties and ease of handling ${ }^{(10,11)}$.

Recently, a new sealer based on a bioceramic has been developed with better properties; as it does not shrink on setting and it is non-toxic. Few studies have investigated the sealing ability of bioceramic sealer (BS), so further researches of its use are required ${ }^{(12)}$.

Lateral compaction is widely accepted filling technique, as it is reliable and simple technique ${ }^{(13)}$. However, it might lead to gaps between gutta-percha cones/sealer and dentin walls due to spreader penetration; there is also a risk of vertical root fractures during compaction forces ${ }^{(14) .}$ Single-cone filling has recently been reviewed with the new sealers and master cone with taper that matches the shape of rotary nickel-titanium instrumentation systems; this could support the use of a single-cone obturation technique. This technique has the merits of reducing microleakage and decrease the possibility of root fracture ${ }^{(15)}$.

Coronal restoration of endodontically treated teeth should provide certain criteria as; esthetic, functional value, a sound and strong remaining tooth structure, and prevent microleakage ${ }^{(16)}$. They are ranging from a relatively small direct restoration like resin composite or amalgam restorations to more complex indirect restorations involving the placement of an intra-radicular post and core and the indirect full coverage restoration ${ }^{(17,18)}$.

When immediately definitive restoration is not possible, a provisional restorative material should be used to prevent root canal system from saliva and microorganism contamination. In some cases, to improve root canal system sealing, an intermediary coronally sealing procedure "intra-orifices barriers" could be used. For such two situations; the restorative materials that having bonding mechanism to tooth structure, such as composite resins, glass ionomers (conventional or resin-modified) and compomers are good options (18-20). The sealing and bonding ability of restorative systems to pulp chamber dentin is challengeable as the pulp chamber dentin has structural and compositional differences from coronal dentin. Moreover, endodontic irrigants or root canal filling materials can adversely affect the bonding of adhesives to pulp chamber dentin ${ }^{(21-22)}$. 
Various studies have evaluated the coronal and apical sealing ability of endodontically treated teeth using different techniques such as dye leakage, electrochemical techniques, bacterial penetration measurement and fluid filtration technique ${ }^{(23-27)}$.

The aim of this present study was to assess coronal bacterial leakage after obturation with single cone technique with MTA based sealer, resin-based sealer and Tagdseal sealer using three different coronal restorative materials in root canal treated teeth.

\section{MATERIALS AND METHODS}

\section{Experimental grouping:}

A total of seventy-two single rooted teeth that were extracted for periodontal and prosthetic reasons were collected for this study and were radiographed to confirm the presence of one canal, mature apex, and absence of resorption or cracks. The teeth were randomly divided into three groups of 24 samples according to the sealer used and then randomly subdivided into 3 subgroups of 8 samples according to the coronal restoration of the specimens . Therefore, there was 9 final groups; I, II, III, IV, V, VI, VII, VIII, IX.

\section{Preparation and obturation of the radicular part}

The selected teeth were immersed in saline solution for 72 hours to maintain hydration .All preparation and obturation procedures were carried out by one operator. After Pulp extirpation, a size 15 K-file (Dentsply, Maillefer, Ballaigues) was inserted into the canal until it was seen at the apical foramen. The working length was determined to $1 \mathrm{~mm}$ short of the apical foramen. The root canals were instrumented using Protaper Next rotary system to X3 file, with intermittent sodium hypochlorite solution and EDTA irrigation, with alternating irrigation with normal saline between irrigation.
For smear layer removal EDTA was used as final canal irrigation. The canals were dried with sterile paper points (Roeko,Colte'ne/Whaledent,Langenau, Germany) before filling. The teeth were randomly divided into three groups of 24 samples according to the sealer used, group 1:Bioceramic sealer (BS), group 2: MTA fillapex (MTA) and group 3: Tagdseal sealer (TG). The sealers were manipulated according to the manufacturers' instructions. The sealers were placed into the canals using the master cone.

\section{Restoration of the coronal part:}

After completion of the root canal sealing, the 3 main groups were divided randomly into three subgroups 8 samples each according to the coronal restorative materials used. The application of the restorative materials was done following the manufactures instructions and the Bluephase curing unit was used (Ivoclar - Vivadent). Subgroup A:Tetric N Bond + Tetric Ceram (Composite; Ivoclar - Vivadent). The coronal prepared cavity wall was first instilled with N-Etch for 15 seconds, and then the conditioned surface was rinsed with a vigorous water spray for 5 seconds and gently air dried "wet bonding". After the etching procedure was completed, Tetric N Bond was applied, brushed for 10 seconds, dispersed with a very weak stream of air and polymerized for 10 seconds. Tetric Ceram (shade A2) was applied in layer of maximum 2 $\mathrm{mm}$, with each layer allowed to polymerize for 20 seconds. Subgroup B: Adhese SE + Compoglass F (Compomer; Ivoclar - Vivadent). Adequate amount of Adhese SE primer was applied by a brush to the coronal cavity surfaces, the primer was brushed into the entire surface for another 15 seconds, excess Adhese SE primer was dispersed with a strong stream of air and then the Adhese SE bond was applied, dispersed with a very weak stream of air and polymerized for 10 seconds. Compoglass F (shade A2) was applied in layer of maximum $3 \mathrm{~mm}$, with each layer allowed to polymerize for 
40 seconds. Subgroup C : riva conditioner + riva light cure (Resin Modified Glass Ionomer "RMGI"; $3 \mathrm{M}$ ESPE). The cavity conditioner (riva conditioner) was first applied in the coronal dental cavity, and the conditioned surface was then rinsed with water and gently air dried "kept moist". riva LC (shade A2) was prepared by activating the capsule and immediately mixed in the amalgamator for 10 seconds and then applied to the cavity using capsule applicator, and each layer $(2 \mathrm{~mm}$ ) was polymerized for 20 seconds.

The final groups were as following: group I used BS sealer and Composite restorative material, group II used BS sealer and Compomer restorative material, group III used BS sealer and Glass Ionomer restorative material, group IV used MTA sealer and Composite restorative material, group V used MTA sealer and Compomer restorative material, group VI used MTA sealer and Glass Ionomer restorative material, group VII used TG sealer and Composite restorative material, group VIII used TG sealer Compomer restorative material and group IX used TG sealer \& Glass Ionomer restorative material

\section{Bacterial leakage measurements:}

The filled tooth was fixed in open bottom $1.5 \mathrm{ml}$ Eppendorf tube. The area surrounding the tooth was sealed with wax. Eppendorf tube containing filed tooth was inserted into $4 \mathrm{ml}$ tube. E. faecalis were inoculated on blood agar and incubated for $18 \mathrm{~h}$ at $37^{\circ} \mathrm{C}$. On day $2,3 \mathrm{ml}$ broth medium was added to the $4 \mathrm{ml}$ tube and $800 \mathrm{ul}$ in the top $1.5 \mathrm{ml}$ Eppendorf tube containing filed tooth. The bacteria and medium in the upper chamber were replaced with freshly grown cultures twice weekly. Bacteria leakage along the root filling was assessed by observation of turbidity in the lower chamber ${ }^{(27)}$.

Bacterial colonies were suspended in PBS and bacterial numbers were measured at a wave length of $600 \mathrm{~nm}$; one optical density unit equals $10^{8}$ cells/ $\mathrm{ml}$. Bacteria $\left(2 \times 10^{5} / \mathrm{ml}\right)$ were added to Eppendorf tube containing filed tooth and incubate at $37^{\circ} \mathrm{C}$ for $18 \mathrm{~h}$. Leakage was evaluated by turbidity in lower chamber in 30-day period "weekly interval".After one, 2,3 and 4 weeks $10 u l$ from the bottom tube was transferred to blood agar plate and streaked using sterile loop and incubated at $37^{\circ} \mathrm{C}$ for $18 \mathrm{~h}$. Bacterial colonies were counted in each group.

\section{Data analysis:}

Data was collected and tabulated then analyzed using SPSS software version. Data was tested for normality before analysis; descriptive statistics were done for all variables. One way ANOVA test was used to comparing between the different means, post hoc pairwise comparison was done using Tukey test. $\mathrm{P}$ values less than or equal 0.05 was considered significant.

\section{RESULTS}

Group I (Bioceramic - Composite) showed the lowest means of bacterial leakage after one, two, three and four weeks of evaluation. On the other hand, the (MTA - Glass Ionomer) material showed the highest means of bacterial leakage $(48.84,52.15$, 47.27 and 48.26) along the evaluation periods respectively. There was a significant difference between the means of the bacterial colonies recorded in the nine groups at one, 2 and 4 weeks; while at 3 weeks the difference was insignificant. Regarding the evaluation of each material during the different evaluation periods, group II, V, VII, VIII and IX showed low means of bacterial colonies after four weeks of evaluation compared with the bacterial colonies means recorded after one week of evaluation, with no statistical significance difference. 
TABLE (1): Pairwise comparison between the different groups after one, two, three and four weeks of evaluations using Tukey test.

\begin{tabular}{|c|c|c|c|c|c|}
\hline \multirow[t]{3}{*}{ Groups } & \multicolumn{4}{|c|}{ Evaluation period } & \multirow{3}{*}{ F (p value) } \\
\hline & One week & 2 weeks & 3 weeks & 4 weeks & \\
\hline & Mean \pm SD & Mean \pm SD & Mean \pm SD & Mean \pm SD & \\
\hline Group I (BS- Composite) & $28.68 \pm 4.18$ & $24.06 \pm 4.29$ & $27.23 \pm 4.94$ & $28.145 \pm 3.73$ & $1.840(0.613)$ \\
\hline Group II (BS- Compomer) & $39.145 \pm 3.13$ & $34.49 \pm 3.67$ & $37.51 \pm 3.84$ & $37.58 \pm 4.17$ & $2.196(0.111)$ \\
\hline Group III (BS - Glass Ionomer) & $40.49 \pm 5.1$ & $37.80 \pm 5.45$ & $38.51 \pm 3.73$ & $41.88 \pm 4.14$ & $1.258(0.299)$ \\
\hline Group IV (MTA- Composite) & $45.91 \pm 4.75$ & $45.91 \pm 4.65$ & $43.83 \pm 6.12$ & $45.91 \pm 4.75$ & $0.331(0.803)$ \\
\hline Group V (MTA-Compomer) & $46.80 \pm 3.78$ & $43.61 \pm 2.88$ & $46.79 \pm 3.87$ & $45.26 \pm 3.29$ & $1.529(0.299)$ \\
\hline Group VI (MTA - Glass Ionomer) & $48.84 \pm 6.75$ & $52.15 \pm 3.57$ & $47.27 \pm 7.13$ & $48.26 \pm 6.36$ & $0.955(0.428)$ \\
\hline Group VII (TG- Composite) & $40.06 \pm 4.26$ & $41.24 \pm 4.15$ & $40.04 \pm 3.49$ & $39.03 \pm 5.38$ & $0.341(0.796)$ \\
\hline Group VIII (TG-Compomer) & $45.32 \pm 5.92$ & $44.80 \pm 5.57$ & $42.60 \pm 6.40$ & $42.50 \pm 3.26$ & $0.583(0.631)$ \\
\hline Group XI (TG - Glass ionomer) & $47.70 \pm 4.87$ & $46.55 \pm 4.33$ & $47.66 \pm 5.01$ & $46.17 \pm 6.98$ & $0.166(0.918)$ \\
\hline F (p value) & $\begin{array}{c}11.878 \\
(0.000)^{*}\end{array}$ & $\begin{array}{c}28.412 \\
(0.000)^{*}\end{array}$ & $\begin{array}{c}0.327 \\
(0.953)\end{array}$ & $\begin{array}{c}12.908 \\
(0.000)^{*}\end{array}$ & \\
\hline
\end{tabular}

\section{SD: standard deviation}

F: one-way ANOVA test

*: The mean difference is significant at $P \leq 0.05$ level.

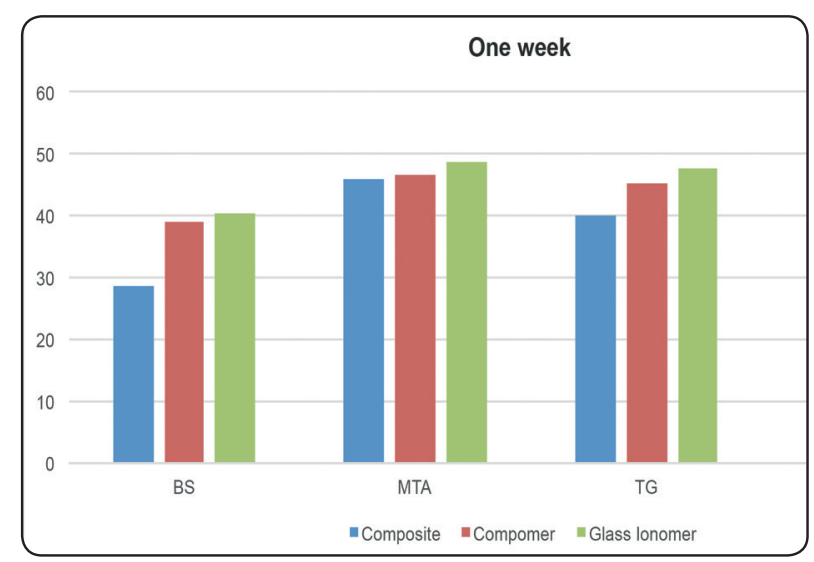

Fig. (1) Bar chart showing the means of bacterial leakage of the 9 groups after one week.

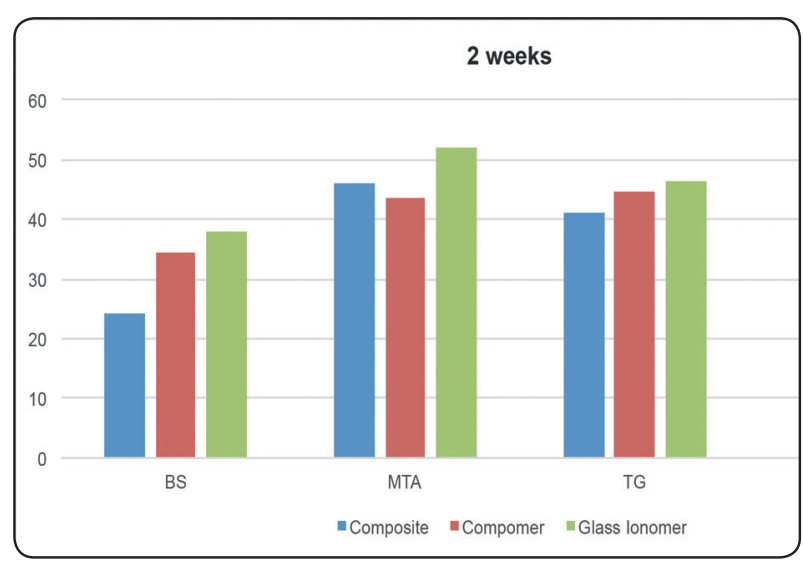

Fig. (2) Bar chart showing the means of bacterial leakage of the 9 groups after two weeks. 


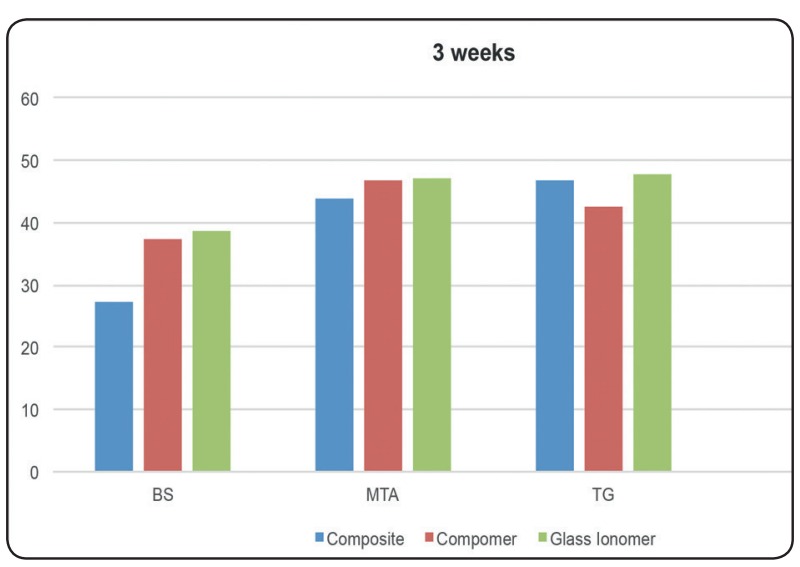

Fig. (3) Bar chart showing the means of bacterial leakage of the 9 groups after three weeks.

\section{DISCUSSION}

Coronal and/or apical leakage enhances the ingress of microorganisms and nutrient that initiate periradicular inflammation and cause failure in endodontic therapy. Adequate marginal sealing between tooth and endodontic restorative material is essential to decrease contamination of the root canal systems during and post endodontic treatment ${ }^{(28-30)}$.

Sealing studies to assess sealers remain essential to determine the most appropriate filling materials for achieving the best outcome. Various studies using gutta percha and different sealers indicate that gutta percha will allow bacterial leakage. While using an adhesive sealer can significantly decrease or inhibit coronal/apical bacterial ingress ${ }^{(6)}$.

As Van der Sluis et al. ${ }^{(31)}$ reported significant differences in leakage between oval and round canals, so in this study, for standardization, teeth with straight single root with round canals were selected. Moreover, to prevent human discrepancies, all the endodontic procedures have been done by one operator while another operator did the coronal restoration.

Dye leakage has been the most technique used to evaluate the sealing ability of canal obturation, it was shown that it has not been completely

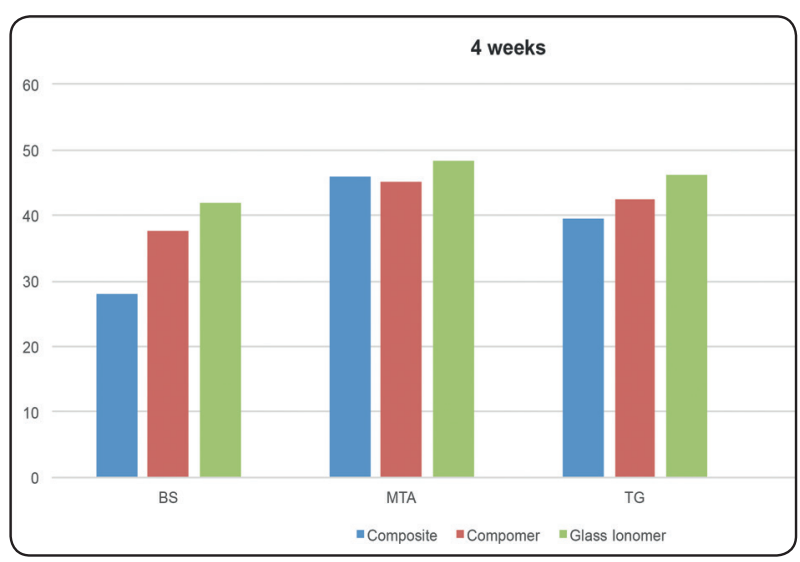

Fig. (4) Bar chart showing the means of bacterial leakage of the 9 groups after four weeks.

reliable. Therefore, microbial culture has been used to give more accurate results and copy the in vivo condition ${ }^{(23,32)}$. Pinheiro et. al ${ }^{(33)}$ stated that the microbial flora within root canals after failure of root-canal therapy was limited to number of grampositive species, facultative anaerobes, mainly $\mathrm{E}$. faecalis. So, E. faecalis have been selected to be used for the microbial testing in the present study.

Removal of smear layer provides better penetration of filling materials into dentinal tubules. In the present investigation removal of smear layer was done using 17\% EDTA and 5.25\% $\mathrm{NaOCl}^{(10,19)}$. This could also assist in enhancing the bond between the filling material and dentin wall, because of the relatively weak bond of the smear layer to the underlying dentine, which may be insufficient to withstand the shrinkage associated with the curing of resins, that provide an avenue for microleakage. ${ }^{(34)}$

Single cone technique is becoming more popular as it is simple and saves time. Researches have shown controversial reports of the accuracy of this technique. More studies are required to have additional information. There are limited data about the sealing properties of bioceramic sealer using single technique specially when conjugated with the restorative materials ${ }^{(35,36) \text {. }}$ 
Different materials have been used to achieve adequate coronal seal like Cavit, intermediate restorative material, GIC, zinc oxide eugenol cement, resin modified GIC, Compomer, composites and recently MTA. Each of these materials has their own benefits and limitations ${ }^{(20)}$. In this present study three different restorative materials have been selected; resin composite with total-etch adhesive (Tetric N Bond + Tetric Ceram), Compomer with self-etch adhesive (Adhese SE + Compoglass F) and resin modified glass ionomer with conditioner (riva conditioner + riva light cure).

The assessment was done for 30 days within this period, most of the samples showed bacterial leakage especially within the first week, (fig 1, table 1); this was in accordance with many previous

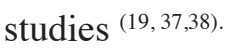

The results of the present study showed that, the specimens of bioceramic sealer that coronally restored by resin composite showed the lowest bacterial leakage. While specimens in which MTA sealer was used and coronally restored by glass ionomer showed the highest bacterial leakage, table (1). These results were in agreement with ${ }^{(19}$, ${ }^{20)}$. While disagreed with the study of Yavari et al. ${ }^{(39)}$, who compared the coronal microleakage of three materials as coronal barriers and they concluded that MTA exhibited less leakage than composite and GI but no significant differences were found between GI and composite groups . The good sealing ability of the BS group could be attributed to the more stable dimensions because of its composition of inorganic minerals ${ }^{(36)}$.

The results of this study showed that leakage still occurred in the bioceramic sealer group, although it was less than that observed in the other groups "Tagdseal and MTA groups". These were in accordance with Koch et al. ${ }^{(12)}$ and Muharsya et.al (36) who compared the sealing ability of bioceramic sealer (BS), and methacrylate resin-based sealer (MRS) by dye penetration. They concluded that BS showed less microleakage in the apical third than MRS.

The good sealing of resin composite restorative material in this study although of the drawback effect of its polymerization shrinkage could be attributed to the adequate bonding of the material to the tooth structure which was total etch adhesive system. Considering that, the frequency and tubular diameter are higher in the pulp chamber than in coronal dentin (22).

Compomer is a polyacid-modified composite, the polymeric phase of the material avoids sensitivity to humidity and could explains the superior seal obtained in comparison to the resin-reinforced ionomer in this study. Although, this greater polymeric content increases the risk of gap formation and consequent leakage due to polymerization shrinkage (40).In the other hand, the improper sealing of resin modified glass ionomer material might be explained by their hydrophilic properties, micro-gaps, and/or porosities which may affect their sealing ability and other physical properties. It also tends to undergo some amount of shrinkage during the setting, which can cause loss of the marginal integrity that leading to microleakage ${ }^{(20)}$.

Resin based sealers were more resistant against bacterial microleakage. This could be attributed to flowability and dimensional stability, enhanced adaptation and better sealing ability to dentine walls $^{(8-10)}$. The results of this study showed that TG sealer which is resin materials was more resistant to bacterial microleakage compared with MTA Fillapex ${ }^{\circledR}$. These results are similar to the results of both Oliveira et al. ${ }^{(28)}$ who evaluated the sealing of MTA Fillapex, Sealapex and AH Plus by fluid movement technique, and they have found that after 180 days AH Plus and Sealapex had the least microleakage, the difference can be attributed to the chemical composition of MTA-based materials. While the results were contradicting to the results of Gomes-Filho et al. ${ }^{(41)}$ who concluded that 
Fillapex® and Sealapex resulted in significantly less microleakage than Endo CPM sealer using dye penetration method.

These differences in leakage results among different studies may be attributed to the number of samples, anatomical complexity of the root canal systems, different sealers and leakage methods selected.

\section{CONCLUSIONS:}

According to the results of this in vitro study, Bioceramic sealer with Composite restorative material showed the least bacterial leakage while MTA sealer and Glass Ionomer restorative material showed the highest mean of leakage .None of the tested materials could fully prevent apical contamination when exposed coronally to microorganisms. However, further long-term researches are recommended to establish the best clinical performance of single gutta-percha filling system with different sealers and restorative materials.

\section{REFERENCES}

1. $\mathrm{Sj} €$ ogren U, Hagglund B, Sundqvist G, Wing K. Factors affecting the long-term results of endodontic treatment. J Endod 1990; 16:498-504.

2. Sj€ogren U, Figdor D, Persson S, Sundqvist G. Influence of infection at the time of root filling on the outcome of endodontic treatment of teeth with apical periodontitis. Int Endod J 1997; 30:297-306.

3. Nair PN. On the causes of persistent apical periodontitis: a review. Int Endod J 2006; 39:249-281.

4. Gomes AC, Nejaim Y, Silva AI, et al. Influence of endodontic treatment and coronal restoration on status of periapical tissues: a cone-beam computed tomographic study. J Endod 2015; 41(10):1614-1618.

5. Zaia AA, Nakagawa R, De Quadros I, Gomes BP, Ferraz CC, Teixeira FB, Souza-Filho FJ. An in vitro evaluation of four materials as barriers to coronal microleakage in rootfilled teeth. Int Endod J $2002 ; 35(9): 729-734$.

6. Chailertvanitkul P, Saunders WP, Mackenzie D. An assessment of microbial coronal leakage in teeth root filled with gutta-percha and three different sealers. Int Endod J1996; 29: 387-392.

7. Saleh IM, Ruyter IE, Haapasalo M, Orstavik D. The effects of dentine pretreatment on the adhesion of root-canal sealers. Int Endod J 2002;35(10):859-866.

8. Cobankara FK, Orucoglu H, Sengun A, Belli S. The quantitative evaluation of apical sealing of four endodontic sealers. J Endod 2006; 32: 66-68.

9. Leal FM, Camargo CHR, Valera MC, Silva GO, Oliveira TR, Junqueira JC. Coronal bacterial leakage in root canals filled with single cone technique and different endodontic sealers. Braz Dent Sci. 2014; 17(2): 57-62.

10. Singh R, Pushpa S, Arunagiri D, Sawhny A, Misra A and Sujatha R. The effect of irrigating solutions on the apical sealing ability of MTA Fillapex and Adseal root canal sealers. J Dent Res Dent Clin Dent Prospects 2016; 10(4): 251-256.

11. Gomes-Filho JE, Watanabe S, Bernabe PF, de Moraes Costa MT. A mineral trioxide aggregate sealer stimulated mineralization. J Endod2009; 35, 256-60.

12. Koch K, Brave D and Nasseh A A 2013 A review of bioceramic technology in endodontics. CE Article_ bioceramic Technology 2013: 6-13.

13. Moazami F, Nabavizadeh MR, Sahebi S. An in vitro evaluation of human saliva penetration in obturated root canals with different pairs of root canal filling materials. Shiraz Univ Dent J. 2010; 10:9-114.

14. Clinton K, Himel VT. Comparison of a warm gutta-percha obturation technique and lateral condensation. J Endod 2001; 27: 692-695.

15. Pereira A C. Single-cone obturation technique: a literature review. RSBO 2012; 9(2): 442-447.

16. Eliyas S, Jalili J, Martin N. Restoration of the root canal treated tooth. Br Dent J 2015; 218(2):53-62.

17. Morgano SM, Rodrigues AH, Sabrosa CE. Restoration of endodontically treated teeth. Dent Clin N Am 2004; 48(2): $397-416$.

18. Gonzaga CC, de Campos EA and Baratto-Filho F. Restoration of endodontically treated teeth. RSBO 2011; 8(3): e33-46.

19. De Castro PH, Pereira JV, Sponchiado EC Jr, Marques AA, Garcia Lda F. Evaluation of marginal leakage of different temporary restorative materials in Endodontics. Contemp Clin Dent. 2013;4(4):472-5. 
20. Divya KT, Satish G, Srinivasa TS, Reddy V, Umashankar $\mathrm{K}$, Rao MB. Comparative evaluation of sealing ability of four different restorative materials used as coronal sealants: An in vitro study. J Int Oral Health 2014;6(4):12-7.

21. Wattanawongpitak N, Nakajima M, Ikeda M, Foxton R M, Tagami J. Microtensile bond strength of etch-and-rinse and self-etching adhesives to intrapulpal dentin after endodontic irrigation and setting of root canal sealer. J Adhes Dent 2009; 11: 57-64.

22. Şermet Elbay Ü, Tosun G. Effect of endodontic sealers on bond strength of restorative systems to primary tooth pulp chamber. JDS 2017: 12(2): 112-120.

23. Beatty RG, Baker PS, Haddix J, Hart F. The efficacy of four root canal obturation techniques in preventing apical dye penetration. J Am Dent Assoc 1989; 119: 633-637.

24. Amditis C, Bryant RW, Blackler SM. The assessment of apical leakage of root-filled teeth by the electrochemical technique. Aust Dent J 1993; 38: 22-27.

25. Carratu P, Amato M, Riccitiello F, Rengo S. Evaluation of leakage of bacteria and endotoxins in teeth treated endodontically by two different techniques. J Endod 2002; 28 : 272-275.

26. Inan U, Aydin C, Tunca YM, Basak F. In vitro evaluation of matched-taper single-cone obturation with a fluid filtration method. J Can Dent Assoc 2009; 75:123-126.

27. Moradi S, Lomee M, Gharechahi M. Comparison of fluid filtration and bacterial leakage techniques for evaluation of microleakage in endodontics. Dent Rest J 2015;12: 109-114.

28. Oliveira SH, Silva GO, Cardoso FG, Vasconcelos RA, Xavier AC. Evaluation of apical leakage in root canals filled with different sealers. Braz Dent Sci. 2012;15(3):32-37.

29. Ray HA, Trope M. Periapical status of endodontically treated teeth in relation to the technical quality of the root filling and coronal restoration. Int Endod J 1995; 28:12-8.

30. Cobankara FK, Adanir N, Belli S, Pashley DH. A quantitative evaluation of apical leakage of four root-canal sealers. Int Endod J 2002;35(12):979-984.

31. Van der Sluis LW, Wu MK, Wesselink PR. An evaluation of the quality of root fillings in mandibular incisors and maxillary and mandibular canines using different methodologies. J Dent. 2005;33(8):683-8.

32. Britto LR, Grimaudo NJ, Vertucci FJ.: Coronal microleakage assessed by polymicrobial markers. J Contemp Dent Pract. 2003 Aug 15;4(3):1-10.

33. Pinheiro ET, Gomes BPFA, Ferraz CCR, Sousa ELR, Teixeira FB, Souza-Filho FG. Microorganisms from canals of root-filled teeth with periapical lesions. Int Endod J 2003; 36: $1-11$.

34. Cobankara FK, Adanr N, Belli S. Evaluation of the influence of smear layer on the apical and coronal sealing ability of two sealers. J Endod 2004;30(6):406-409.

35. Hegde V and Arora S. Sealing ability of three hydrophilic single-cone obturation systems: An in vitro glucose leakage study. Contemp Clin Dent. 2015; (6): S86-S8.

36. Muharsya Y, Usman M and Suprastiwi E. Comparison sealability of root canal obturation using bioceramic sealer and methacrylate resin-based sealer. J Phys Conf Ser 2017; 884012111

37. Madarati A1, Rekab MS, Watts DC, Qualtrough A. Timedependence of coronal seal of temporary materials used in endodontics. Aust Endod J. 2008 Dec;34(3):89-93.

38. Srivastava PK, Nagpal A, Setya G, Kumar S, Chaudhary A, Dhanker K. Assessment of Coronal Leakage of Temporary Restorations in Root Canal-treated Teeth: An in vitro Study. J Contemp Dent Pract. 2017;18(2):126-130.

39. Yavari H, Samiei M, Eskandarinezhad M, Shahi S, Aghazadeh M, Pasvey Y. An In Vitro Comparison of Coronal Microleakage of Three Orifice Barriers Filling Materials. Iranian Endodontic Journal IEJ 2012;7(3):156-160

40. Rosales-Leal JI, Olmedo-Gaya V, Vallecillo-Capilla M, Luna-del Castillo JD. Influence of cavity preparation technique (rotary vs. ultrasonic) on microleakage and marginal fit of six end-root filling materials. Med Oral Patol Oral Cir Bucal. 2011 Mar 1;16 (2):e185-9.

41. Gomes-Filho JE, Moreira JV, Watanabe S, Lodi CS, Cintra LT, Dezan E, Junior, et al. Sealability of MTA and calcium hydroxide containing sealers. J Appl Oral Sci. 2012; 20:347-351. 